\title{
Numerical Taxonomy, Convergence, and Evolutionary Reduction
}

WILLIAM L. BROWN, JR. 


\title{
Numerical Taxonomy, Convergence, and Evolutionary Reduction
}

\author{
WILLIAM L. BROWN, JR.
}

Let us be clear from the beginning-I am writing to criticize numerical taxonomy, not quantitative systematics. I am sure that measurement and mathematical methods will and should be much more widely employed in systematic studies. It should also be understood that numerical taxonomy, by which I mean specifically the doctrine and methods outlined by Sokal and Sneath (1963) in their book of this title, is to me not without interest, import, and potential usefulness for systematic biology. But $I$ intend to show that in at least one important respect, numerical taxonomy is headed in the wrong direction.

I am not going to attempt to deal with mathematical questions, and I am going to skip over the obvious objections based on the difficulty of properly analyzing characters, so that I can get to the subject that interests me most. While considering this fault in numerical taxonomy, I hope to bring the criticism around to a more constructive position by hinting at an approach to systematics that the numerical taxonomists might find worth trying.

The aspect $I$ have chosen to discuss deals with phyletic convergence, a term that I here interpret broadly to include the finergrained phenomenon, parallelism. Michener and Sokal (1957) make the following statement:

Possible parallelisms present a difficult problem. The amount of evolution, after divergence from a common stem, of two forms that have evolved in a parallel manner, would be underestimated by our method, as well as by customary systematic methods.

The authors claim that their studies of saturniid moths and megachilid bees show relatively few parallel characters.
We believe that much of the difficulty due to parallelisms is eliminated in our study by the large number of characters used. Parallelism or convergence affecting only a few characters would not greatly influence our measure of relationship.

It hardly needs to be added that convergence or parallelism affecting a large proportion of the characters used would seriously upset the conclusions of the numerical taxonomist, as well as those of many a traditional phylogeny-builder. Perhaps it was uneasiness about evolutionary convergence that led Sneath and Sokal (1962) to pose this rhetorical question.

Suppose an absurdly extreme overall convergence had occurred so that two forms were almost indistinguishable and could readily and successfully hybridize: What is the purpose of separating them on grounds of ancestry when in all other attributes they are the same?

We accept this question as "absurdly extreme" indeed (at least at the metazoan level), but we answer it anyway: We separate the two forms if we know their ancestry, because the history of this situation is of overriding biological importance. It should be borme in mind that systematic biology is not merely an arrangement for gathering and filing data on the diversity of living organisms; it is also, with genetics and ecology, one of our main hopes of understanding how evolution occurs. That understanding is clearly fragmentary right now, despite the advances of Darwin and the geneticists.

Let us examine the case of the convergence that may not be "absurdly" extreme but is at least extreme enough to threaten taxonomic judgment. In the group I work on (the ants), the old tribe Dacetini has contained convergent elements of three separate tribes, and genera actually repre- 

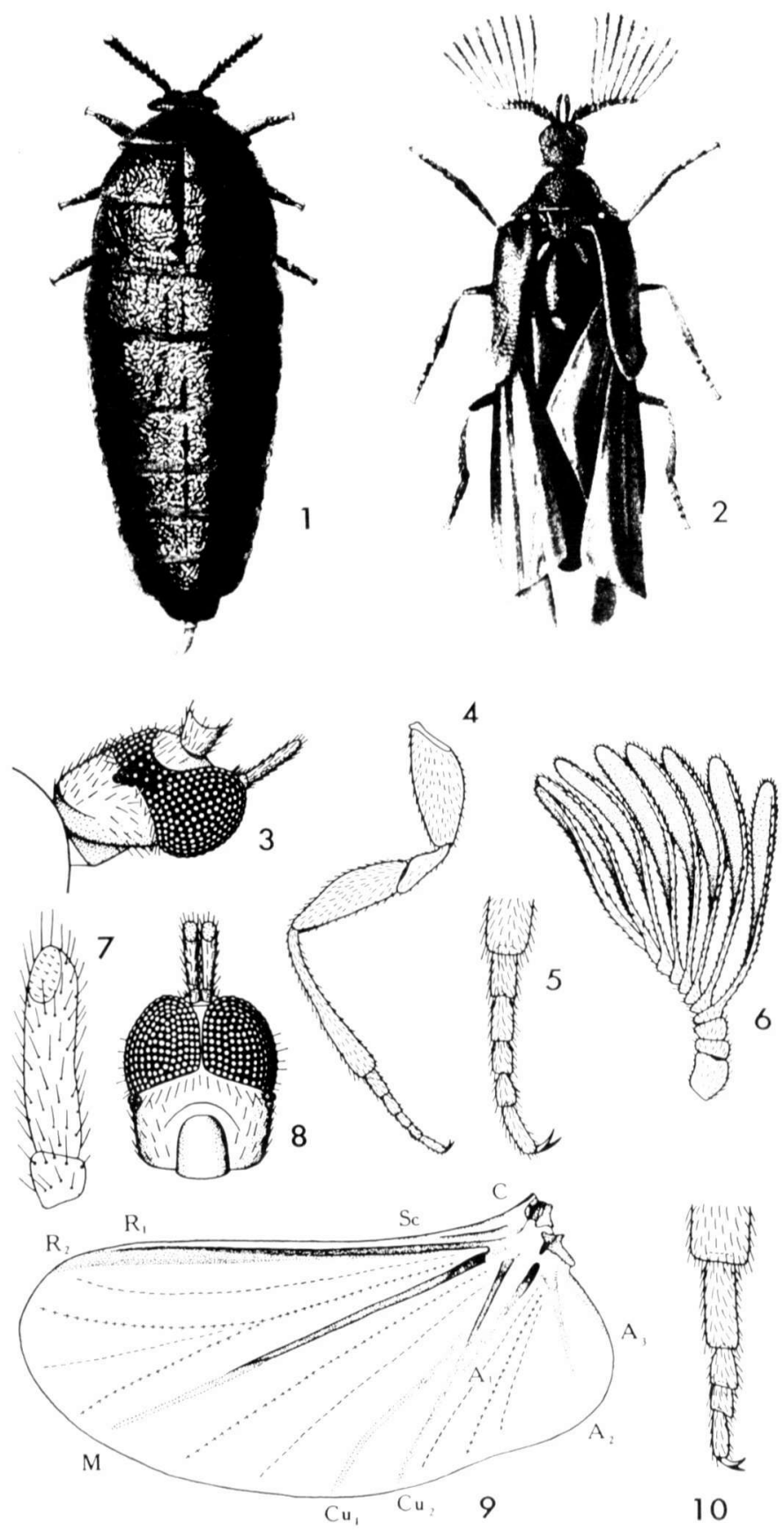

Figs. 1-10. Rhipidius quadriceps (Rhipiphoridae). Fig. 1, adult female. Figs. 2-10, adult male: 2, habitus drawing; 3, lateral view of head; 4, anterior leg; 5 , tarsus of anterior leg; 6 , antenna; 7 , maxillary palp; 8, ventral view of head; 9 , left (hind) wing; 10, hind tarsus (after C. Besuchet). 
senting two additional tribes might well have been placed there in recent years if the classification had been done on either the old basis or by numerical taxonomy (Brown and Wilson, 1957, 1959).

One might also point to the subfamily Dorylinae, the army ants, the different tribes of which share an impressive number of characters, both morphological and behavioral, in worker, female and male castes, in larval morphology, in the behavior, physiology and ecology of the colony taken as a whole, and in the taxa of inquilines they harbor. In spite of these detailed resemblances, all of which are no doubt adaptively correlated with the specialized armyant way of life, I suspect that three and possibly four completely independent lineages make up the Dorylinae as the subfamily now stands in the books. This suspicion is based on major differences noted in internal characters and on other considerations too complicated to consider here; the case is currently under study. The literature of zoology, especially in recent times, is full of cases. in which formerly "solid" higher taxa turn out to be polyphyletic after careful study.
The fact is that evolution into specialized adaptive zones commonly affects whole complexes of characters more inclusively than the numerical taxonomists seem to realize. I could most comfortably discuss several more interesting cases of convergence that have caused trouble in ant taxonomy, but I have chosen instead to make my point in more detail by comparing two lineages of degenerate parasitic beetles. I refer to the family Rhipiphoridae and the superfamily Stylopoidea, or Strepsiptera, both of which are regarded in the prevailing interpretations as coleopterous stocks (Crowson, 1955).

The Rhipiphoridae are an entomophagous offshoot of the primarily phytophagous (occasionally entomophagous) family Mordellidae, a major group of heteromerous beetles. The rhipiphorids reach the peak of their parasitic specialization in subfamily Rhipidiinae, which is composed of internal parasitoids of cockroaches (Blattaria). Figures 1 to 10,13 and 16 show Rhipidius quadriceps. Characters especially worthy of note here are the small, narrow, hairy elytra of the male, the coarsely facetted "raspberry" eyes, the broad fan-like male hind wings with radiate venation, the uniflabellate male

Table 1.-A Comparison of Twenty Obvious Characters of the Aberkant Beftle Families Rhipiphoridae (Subfamily Rhipidinae) and Mengeidae.

\begin{tabular}{lcc}
\hline \multicolumn{1}{c}{ Character } & $\begin{array}{c}\text { Rhipiphoridae } \\
\text { (Rhipidiinae) }\end{array}$ & $\begin{array}{c}\text { Stylopoidea } \\
\text { (Mengeidae) }\end{array}$ \\
\hline Spiracle on Abdom. VIII (cucujoid base char.) & 0 & 0 \\
Adult trochanters & $+($ all legs) & in legs 1,2 ? \\
o tarsal segments & $5-5-4$ or less & $5-5-5$ \\
Wing shape fan-like, vannal area developed & + & + \\
Venation radiating & + & + \\
\& wingless, modified for endoparasitism & + & + \\
q with legs & + & + \\
Adult raspberry eyes & + & + \\
Pronotum reduced & + & + \\
Internal parasites of: & Blattaria & Thysanura \\
Hypermetamorphosis & + & + \\
"Triungulin" primary larva (several chars.) & + & + \\
Larvae: trochanters & + & $0 ?$ \\
Elytra reduced, narrow & + & + \\
Elytra soft & + & + \\
Elytra hairy & + & + \\
Gonoforceps of of genitalia & + & 0 \\
Antennal segments o & $6-11$ & $4-7$ \\
Antennal segments $\$$ & $6-11$ & $4-5$ \\
s antennae flabellate & + & +
\end{tabular}


antennae, the wingless, broad form of the adult female, and the peculiar series of traits marking the so-called "triungulin" firstinstar larva. The adult tarsi have the heteromerous base number 5-5-4, or 5 segments on the forelegs, 5 on the middle legs, and 4 on the hind legs.

Characters of the Mengeidae, most primitive of stylopoid families, are shown in Figures $11,12,15$, and 18. Some of the more
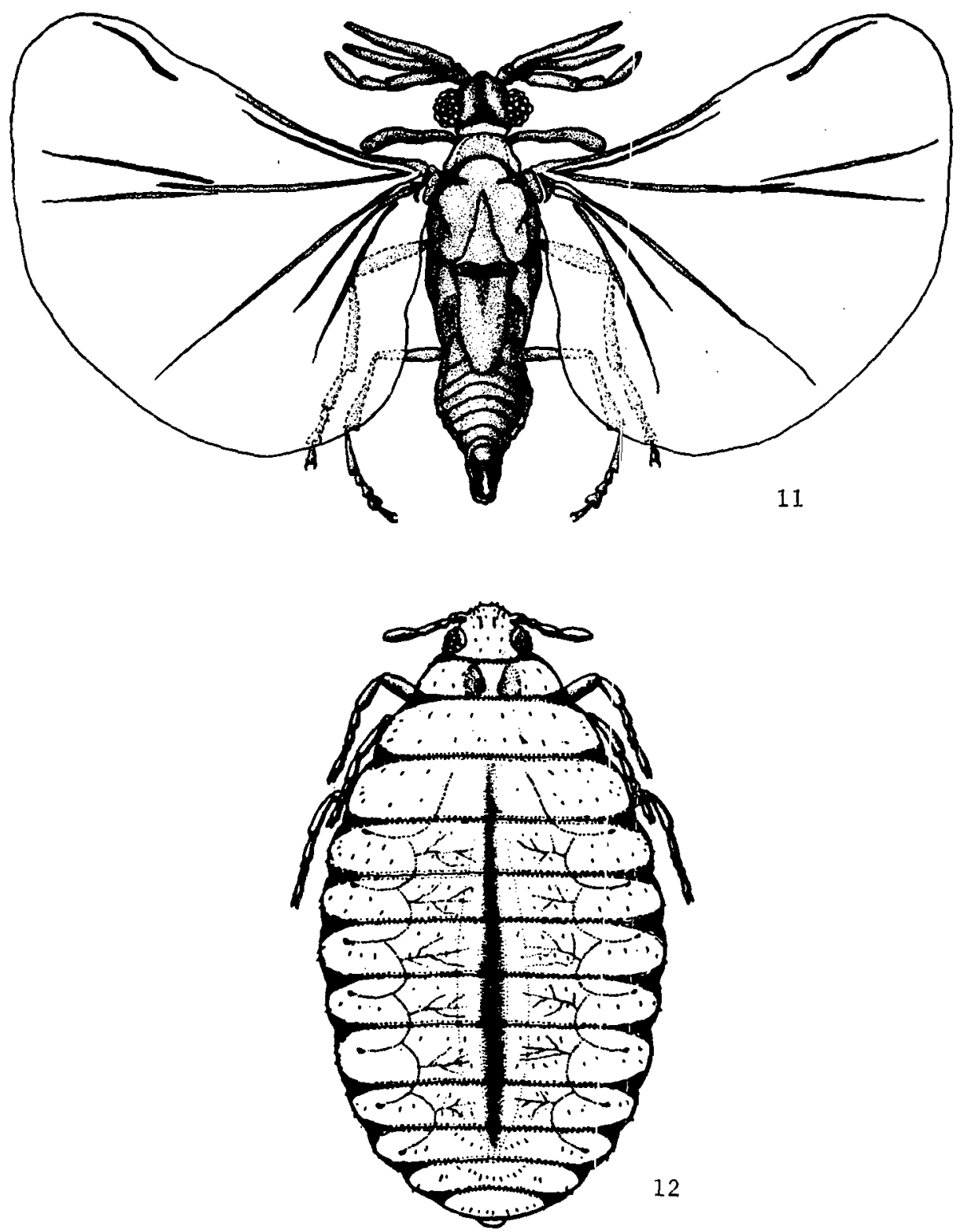

FIgs. 11 and 12. Representative adult Stylopoidea of the primitive family Mengeidae. Fig.11, Triozocera mexicana, adult male (after R. M. Bohart). Fig. 12, jexenos laboulbenei, adult female (after Parker and Smith). 
striking similarities and differences between rhipidiines and mengeids are arrayed in tabular form (Table 1). This table could be extended to other similarities and differences by going into finer and finer points, and probably by studying features of internal anatomy, cytology, physiology, ecology, and behavior that are not now known. This could be done for the similar first-instar "triungulin" larvae, for example, although I have indicated in the table only the probable difference in presence vs. absence of larval trochanters. Another difference lies in the apparent absence of true antennae in the mengeid larva. So far as external character analysis goes, however, there seem to be as many points of similarity as there are of difference between rhipiphorid and mengeid triungulins.

Taking all the characters together, we can make a reasonably strong case for the relationship of Rhipidiinae and Mengeidae. In most of the few known character differences, we see that the mengeid character represents a reduction from the state of the rhipidiine character, so that one might be inclined (as some past authors have been) to derive the stylopoid line from the rhipiphorid stock. There is at least one character, however, that gives taxonomists pause: The tarsi of male mengeids are all 5-segmented. This means that the mengeid male has one more tarsal segment in each hind leg than do the rhipidiines. Furthermore, may it be noted that the Rhipiphoridae and their putative mordellid ancestors belong to a large division of the Coleoptera, the Heteromera, in which the hind tarsus never has more than 4 segments. If the numerical taxonomists will not grant us more phyletic weight for this little tarsal segment, at least they will have to admit that it is a trait of more than routine interest to the phylogenist.

\section{Character Weighting}

The numerical taxonomists have found common cause with a scattering of recent anti-phylogenetic, and often even antievolutionary, writers. Some members of this uneasy alliance will accept indication of phylogenetic relationships as a result of systematic study, but none will condone the use of phyletic reasoning in constructing a classification. I should at this point strongly affirm my belief in phyletic data and logic both as conclusions of systematic investigations and as contributory necessities toward raising classifications in the first place. This is not to say that we should construct a complete phylogeny first, and then our classification. But judicious observation will show us, as it has shown many taxonomists in the past, that some characters tend to evolve in definite directions with high probability. This is why we must give these characters a greater weight in phylogenetic reasoning.

We have already seen, in the case of the tarsal segmentation of the Coleoptera (Rhipiphoridae and Stylopoidea), that phylogenetic weighting is a real component of systematic judgment. But how, exactly, does weighting work?

The answer to this question calls for an assessment of standard phylogenetic thinking-a difficult task considering that much of this thought is implicit and obscure. The taxonomist often has a feeling for the primitive or derivative aspects of the taxa he studies, but most taxonomists are hard put to set this intuition to logic, and they tend to resort to the circular reasoning about which numerical taxonomists rightly complain. It seems to me that there exist certain regularities in evolution above the species level that are the basis of all good phylogenetic reasoning, whether implicit or explicit. Perhaps the tarsal count of the beetles gives us an important clue that we can use as an opening toward a modern study of this question.

It seems that the main reason why most authors have refused to derive the stylopoids from the rhipiphorids is their feeling that the addition of a tarsal segment, to make up the five of the hind tarsus of primitive stylopoids from the four of Rhipiphoridae (and related Heteromera), is an evolutionary event of such low probability that it has received no significant consideration. But why is the simple addition of one small 

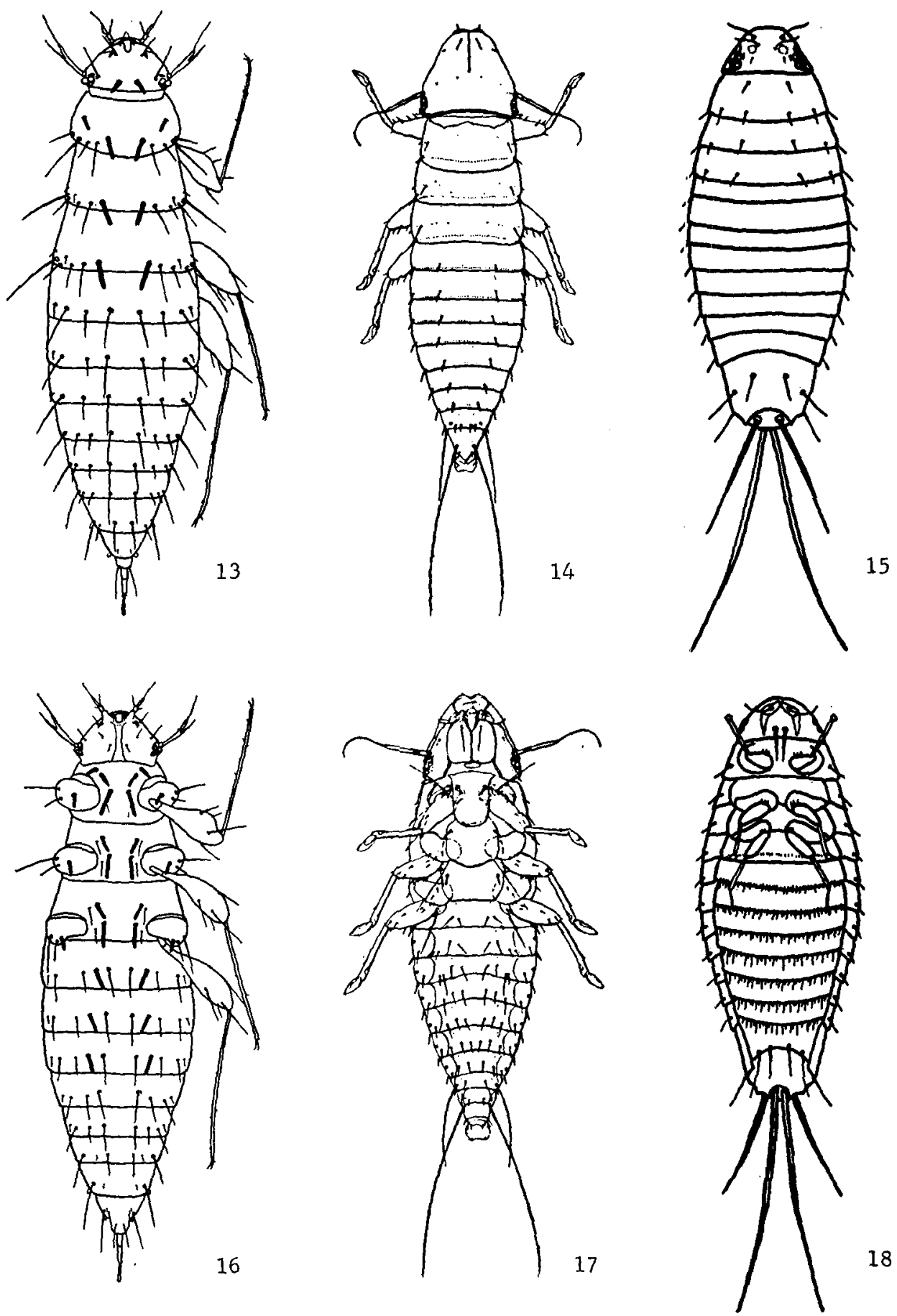

FIGs. 13-18. "Triungulin" (first instar) larvae of representative rhipiphorid beetles and a mengeid stylopoid, dorsal views above, ventral views below. Figs. 13 and 16, Rlipidius quadriceps, Rhipiphoridae (after Besuchet). Figs. 14 and 17, Macrosiagon flabellatum, Rhipiphoridae (after Grandi). Figs. 15 and 18, Eoxenos laboulbenei, Mengeidae (after Bohart). 
segment on each hind tarsus denied by the overwhelming majority of responsible workers on beetle taxonomy? The answer is that they believe that among Coleoptera a change in the number of tarsal segments, such as appears to have taken place many times in different lines, has always resulted in a decrease. The reason for this belief is again not obvious. When asked why he believes it, the coleopterist is likely to reply something such as, "The reduced number is found most often in forms that are derivative as judged on other characters, and the larger number is found in primitive forms of the same group." In other words, he implies some sort of correlation among characters. However, when considering a restricted group, such as a genus or tribe, one often finds that it is "primitive" in one or more characters, but "derivative" in others, so that the correlation, in the strict sense of the term, may be weak or non-existent at this level.

Nevertheless, if one considers very large groups, such as most insect families, superfamilies, and orders, a correlation of a stronger sort is often so evident that we commonly are able to speak of the "lower" and "higher" genera of this or that family with some degree of confidence. But what gives us this confidence?

It seems to me that the answer lies with a rule or principle that we have all absorbed without perhaps thinking much about it in any explicit way: This we may call the rule of evolutionary reduction. It is exemplified by the statement, familiar, I am sure, to all college botany students, to the effect that the flowers of higher plants have tended to evolve from a condition of large, indefinite numbers of parts toward small, definite numbers. The rule of reduction has been explicitly recognized by plant morphologists (e.g., Eames, 1936), and is perhaps implicit in such "Laws" as those of Dollo or Meyrick, as well as in the writings of many other zoologists.

Stated in a crude and general way, the rule of reduction is simply that a gross evolutionary change in a given character is more likely to be a reduction than an elaboration.

To avoid the difficulties of defining "reduction" and "elaboration," we may for the moment restrict ourselves to considering only meristic characters-characters that can be counted as integral units, such as the vertebrae of a fish or the segments of an insect antenna. The rule of reduction then becomes (for metazoan animals, at least): For macroscopic meristic characters in general, a phylogenetic change in number much more frequently results in a decrease than in an increase. Putting it another way, we may say that for any evolutionary span of time the probability that a given meristic character will lose in number is much greater than the probability that it will gain. When we compare "lower" and "higher" genera of a family, for instance, we generally associate large counts for meristic characters in the "lower" genera, and vice versa. We can frequently test the direction of evolution in such cases by (1) the direct chronological evidence of the fossil record (e.g., the decrease in number of dermal skull bones during the fossil history of the vertebrates, or loss of some longitudinal wing veins in the record of the insects); or (2) by the interpretation of regressive "vestigial" characters.

So far as I can tell from a spot check of actual groups (Formicidae as well as $\mathrm{Hy}$ menoptera and Arthropoda in general, Diptera, Rhipiphoridae, and Stylopoidea as well as Coleoptera in general, Vertebrata), following generally accepted and in the main stable classifications for each group, the meristic reduction rule holds extraordinarily well. The exceptions are conspicuous because they run against the "reductive current" of the remaining characters. For instance, Prionus species have 12-25 antennal segments as against the "base number" of 11 for other Cerambycidae and for beetles in general; therefore, it seems clear that this is one case in which the lesser probability of a meristic increase has been realized. It should be noted that the idea of a "base number" or "primitive pattern" is very important to phylogeneticists. 
Among the ants (family Formicidae), the maximum normal antennomere counts are 13 in the males, 12 in females (including workers); the maxillary and labial palpi have at most 6 and 4 segments respectively; and 5 is the invariable number of tarsomeres. It can scarcely be coincidence that wasp groups showing many other similarities to the ants also display these basic numbers in their more generalized species. In even the lowest phytophagous Hymenoptera, we find the same "basic" numbers of palpomeres (6 and 4) and tarsomeres (5), although the antennomeres are basically more numerous (and more variable in number). Against a general background of phyletic reduction throughout the order, the "second trochanter" found in many phytophagous and parasitic Hymenoptera (a piece apparently split off from the distal end of the femur, lost again in the higher families of the order) shows up as a "secondary increase" character like that of the extra antennomeres in Prionus. The pentamerous tarsal count, on the other hand, is the usual one among Hymenoptera, and no doubt carries back eventually to protoperlarian ancestors.

Meristic characters are not always so helpful, and within smaller taxa such as genera and tribes few or none of them may vary enough to give a clear picture of phyletic progression. So it is in the specialized ant genus Strumigenys, with over 150 known species (Brown, 1962); one cannot yet say with certainty in this genus which characters (and consequently, which species) are primitive, and which are derivative.

It is nonetheless possible to arrange the species of Strumigenys in branching relationship-chains, or "open-ended morphoclines," without making a hard-and-fast decision as to which free end of the chain represents the primitive condition. As evidence gathers, in the form of newly discovered species and closer investigation of the ones already known, it is often possible to "polarize" such a morphocline-that is, to show its probable evolutionary direction(s) and to point out the loose chain-end that is most likely primitive. Elements of the theory of morphoclines are set forth in an apparently neglected paper by Maslin (1952) in Systematic Zoology; this article is sensible reading for any systematist. But even before a happy state of phylogenetic polarity is attained, the open-ended morphocline can be a valuable basis for classifying and thinking about any taxon above the species level, as I have found in working with the aforementioned genus Strumigenys and other ant groups.

\section{Possibilities for the Future}

It may well be that the reasoning used in constructing a morphocline, taking account of the reduction rule, is a better way to approach classification and phylogeny than the best that numerical taxonomy has to offer. One riotes that numerical taxonomy has worked out rather poorly in the mosquito genus Aedes, where Rohlf (1963a, b) has not been able to align larval- and adultbased systems in spite of the employment of a large number of characters from both adults and larvae. Furthermore, two different method: of analysis yielded different results for Fiohlf, even for the same stages of the same species-field (Barr and Chapman, 1964). One wonders how a reductionmorphocline: approach might work on this collection of: Aedes species; there has been no opportunity to try it yet.

In my opinion, numerical taxonomy's chief virtue has been its need to see the characters systematically and completely compared for all taxonomic units. The best modern form for such a comparison is a matrix in which every taxon is listed against every character used in the study. This form has been used by many taxonomists in past years, especially for the "rough work" of keymaking. It should be developed and consciously used much more widely in systematic work.

\section{Summary}

1. Numerical taxonomy is inadequate to deal with systematic situations involving aldaptive convergence since these 
situations may commonly involve too large a proportion of taxonomic traits.

2. Examples are cited of likely convergent taxa that would probably be interpreted wrongly by numerical taxonomy, as they have been by conventional taxonomy.

3. Of these taxa, the rhipiphorid and stylopoid beetles are dealt with in detail, and their non-cognate relationship is demonstrated mainly by their difference in a minor character, segmentation of the hind tarsus.

4. Weighting of such characters is covered by a proposed rule of evolutionary reduction, considered to be implicit in most phylogenetic arguments. This rule is stated formally for the case of meristic characters. For macroscopic meristic characters in general, a phylogenetic change in number much more frequently results in a decrease than in an increase.

5. Phylogenetic studies ought to benefit from the conscious application of the reduction rule yardstick and from extension of the morphocline concept of Maslin.

\section{Acknowledgments}

I have been greatly helped in writing this paper by an introduction to the literature of the Rhipiphoridae and the Stylopoidea furnished by R. B. Selander, and by ideas gained through conversations with colleagues, especially A. J. Eames, H. E. Evans, J. G. Franclemont, H. F. Howden, and E. O. Wilson. It is not implied that these individuals necessarily support all of the views expressed above.

\section{REFERENCES}

Barr, A. R., and H. C. Chapman. 1964. Mosquito classification. Systematic Zool. 13:100-101.

Brown, W. L., JR. 1962. The neotropical species of the ant genus Strumigenys Fr. Smith: Synopsis and keys to the species. Psyche 69:238-267.

Brown, W. L., Jr, and E. O. WILson. 1957. Dacetinops, a new ant genus from New Guinea. Brev. Mus, Comp. Zool. Harv. 77:1-7.

1959. The evolution of the dacetine ants. Quart. Rev. Biol. 34:278-294.

Chowson, R. A. 1955. The natural classification of the families of Coleoptera. Nathaniel Lloyd, London.

EAMEs, A. J. 1936. Morphology of vascular plants. Lower groups. McGraw-Hill, New York.

Mascin, T. P. 1952. Morphological criteria of phyletic relationships. Systematic Zool. 1:49-70.

Michener, C. D., and R. R. Sokal. 1957. A quantitative approach to a problem in classification. Evolution 11:130-162.

Rohlf, F. J. 1963a. Congruence of larval and adult classifications in Aedes (Diptera: Culicidae). Systematic Zool. 12:97-117.

1963b. Classification of Aedes by numerical taxonomic methods (Diptera: Culicidae). Ann. Ent. Soc. Amer. 56:798-804.

Sneath, P. H. A., and R. R. Sokal, 1962. Numerical taxonomy. Nature 193:855-860.

Sokal, R. R., and P. H. A. SNeAth, 1963. Numerical taxonomy. W. H. Freeman, San Francisco and London.

WILLIAM L. BROWN, JR. is Associate Professor of Entomology at Cornell University, Ithaca, New York. A substantially similar version of this paper was read as part of a symposium on numerical taxonomy at the XIIth International Congress of Entomology, London, July 1964, but it will be published in the Proceedings of the Congress only in abstract form. 